\title{
Comparative DNA Analysis of Solid Tumors by Flow Cytometric and Image Analyses of Touch Imprints and Flow Cell Suspensions
}

\author{
TARIK M. ELSHEIKH, M.D., JAN F. SILVERMAN, M.D., \\ JANET W. MCCOOL, B.A., SCT(ASCP), AND ROGER S. RILEY, M.D., Ph.D.
}

\begin{abstract}
Comparative DNA analysis by flow cytometric (FCM) and image analyses (IA) has shown a high concordance rate. When present, discordance has been attributed to the presence of aneuploid cell populations detected only by IA, yet missed by FCM. This phenomenon has been explained by loss of aneuploid cells during FCM cell processing, differences in sampling area, or misinterpretation of the DNA histograms. To determine which factors are responsible for the discordance between IA and FCM, 82 fresh solid tumors from various sites were examined. Flow cytometric analysis was performed on cell suspensions isolated from the tumors, whereas IA was performed on touch imprints (IAT) and on cytosmears of the same cell suspension used for FCM (IAF). Comparison between IAT and IAF (IAT/IAF) assessed cell processing and sampling area differences, whereas IAF/FCM comparison assessed differences in apparatus and methodology as possible contributing factors to discordance. Furthermore, DNA histograms of IAT, IAF, and FCM were analyzed in the discordant cases to determine whether the discor-
\end{abstract}

dance was due primarily to different cell populations detected (true discordance) or due to differences in histogram interpretation of the same cell populations (false discordance). IAT/IAF and IAF/FCM concordance rates $(90 \%$ and $88 \%$ ) were not significantly different from that of IAT/FCM (87\%). False discordance accounted for most of the discordant cases in IAT/FCM comparison (six cases, $67 \%$ ), whereas true discordance was seen in three cases. In all three truly discordant cases, the DNAaneuploid cell populations detected only by IAT yet missed by FCM were also detected by IAF. This study demonstrates that discordance between IA and FCM is probably not due to cell loss during FCM cell processing or sampling area differences, but may be due to differences in assessing DNA ploidy in the interpretation of IA histograms and/or dilution of aneuploid cells by normal diploid cells in FCM. (Key words: DNA analysis; Flow cytometry; Image cytometry; Discordance) Am J Clin Pathol 1992; 98:296-304
Quantitative DNA analysis has a primarily prognostic significance in examination of solid tumors. ${ }^{1-7}$ Flow cytometric analysis (FCM) has been the standard method used to evaluate such tumors. More recently, image analysis (IA) has also been used to evaluate the DNA content of neoplasms. Comparative studies using FCM and IA showed high concordance rates ranging from $76 \%$ to $91 \%$ and accordingly low discordance rates. ${ }^{8-14}$ Most of the

From the Department of Pathology and Laboratory Medicine, East Carolina University School of Medicine, Greenville, North Carolina.

Presented in part at the Fall Meeting of the American Society of Clinical Pathologists, September 1991, New Orleans, Louisiana.

Dr. Elsheikh was a finalist for the Pathology ASCP/CAP Pathologist Resident awards competition in anatomic pathology.

Received for review October 25, 1991; revised manuscript accepted for publication March 20, 1992.

Address reprint requests to Dr. Silverman: Department of Pathology and Laboratory Medicine, East Carolina University School of Medicine, Greenville, North Carolina 27858-4354. discordant cases showed DNA-aneuploid cell populations detected only by IA and missed by FCM.12.13.15 Several factors explaining this missed aneuploidy have been proposed by a few investigators, ${ }^{8.10 .12,16-19}$ but no study has objectively demonstrated any one factor to be independently responsible for discordance between IA and FCM. Some of these possible factors include loss of aneuploid cell populations during FCM cell processing, sampling area differences between IA touch imprints and FCM cell suspensions, ${ }^{8.12 .16}$ dilutional effect in FCM by inflammatory cells and benign stromal and/or epithelial cells, ${ }^{10,17,18^{\circ}}$ and differences in interpretation of DNA histograms. ${ }^{8.12 .16 .19}$

To determine which factors are responsible for the discordance between IA and FCM, we performed FCM on cell suspensions isolated from solid tumors and performed IA on touch imprints of the tumors (IAT) and on cytosmears prepared from the same cell suspension used for FCM (IAF). We performed a three-way comparison using 
FCM, IAT, and IAF and assessed the effects of various factors, such as differences in sampling area and methodology, on concordance rates. Furthermore, we examined the discordant cases to determine whether discordance was due predominantly to different aneuploid cell populations detected by IA and FCM, or due to differences in interpretation of the histograms.

\section{MATERIALS AND METHODS}

Eighty-four specimens of 82 tumors from various sites were examined prospectively (Table 1). Fresh touch imprints of tumors were prepared for image analysis (IAT). The same piece of tissue used to prepare the touch imprint was disaggregated to prepare a cell suspension for FCM. In addition, cytosmear preparations of the FCM cell suspension, before propidium iodide staining, were prepared for image analysis (IAF).

\section{Flow Cytometric Analysis}

J

Single cell suspensions were prepared for FCM by mechanical disaggregation of the fresh tumor sample followed by filtration through a piece of fine nylon mesh $(45-\mu \mathrm{m}$ pore size) and centrifugation to remove debris and cell

TABLE 1. TUMORS ANALYZED

\begin{tabular}{|c|c|c|}
\hline Site & Diagnosis & $\begin{array}{c}\text { No. of } \\
\text { Cases }\end{array}$ \\
\hline Bladder & Transitional cell carcinoma & 3 \\
\hline \multirow[t]{4}{*}{ Brain } & Ependymoblastoma & 1 \\
\hline & Meningioma & 1 \\
\hline & Astrocytoma & 2 \\
\hline & Ependymoma & 1 \\
\hline \multirow[t]{4}{*}{ Breast } & Infiltrating ductal carcinoma & 15 \\
\hline & Medullary carcinoma & 3 \\
\hline & Papilloma & 1 \\
\hline & Hyperplasia/fibrosis & 2 \\
\hline \multirow[t]{2}{*}{ Colon } & Adenocarcinoma & 13 \\
\hline & Adenoma & 1 \\
\hline \multirow[t]{2}{*}{ Kidney } & Renal cell carcinoma & 2 \\
\hline & Wilms' tumor & 3 \\
\hline Liver & Metastatic carcinoma & 1 \\
\hline \multirow[t]{4}{*}{ Lung } & Squamous cell carcinoma & 2 \\
\hline & Adenocarcinoma & 3 \\
\hline & Osteosarcoma & 1 \\
\hline & Carcinoid & 1 \\
\hline \multirow[t]{2}{*}{ Lymph node } & Metastatic adenocarcinoma & 4 \\
\hline & Lymphoma & 1 \\
\hline Ovary & Adenocarcinoma & 6 \\
\hline Spleen & Lymphoma & 1 \\
\hline Stomach & Adenocarcinoma & 3 \\
\hline Testis & Seminoma & 1 \\
\hline \multirow[t]{2}{*}{ Thyroid } & Papillary carcinoma & 1 \\
\hline & Hashimoto's thyroiditis & 1 \\
\hline \multirow[t]{4}{*}{ Uterus } & Adenocarcinoma & 5 \\
\hline & Malignant mixed mesodermal tumor & 1 \\
\hline & Adenosquamous carcinoma & 1 \\
\hline & Leiomyosarcoma & 1 \\
\hline
\end{tabular}

clumps. ${ }^{20}$ Cells were prepared for FCM DNA analysis by a modification of the method of Krishan, ${ }^{21}$ using propidium iodide as a DNA-specific fluorochrome. Flow cytometric analysis was performed on an EPICS C flow cytometer (Coulter Corp., Hialeah, FL) optimized for linear red fluorescence signal detection with the use of fluorochrome-labeled microspheres (DNA Check Beads, Coulter Corp.), chicken red blood cells, and cryopreserved normal human lymphocytes. Nonlinear events were excluded from flow cytometric DNA analysis by gating on a histogram of the linear red fluorescence signal versus forward angle light scatter. Chicken red blood cells were used as a DNA internal standard during specimen analysis, whereas cryopreserved, thawed human lymphocytes were used as reference cells. Standard and reference cells were admixed with the test sample before staining, and this specimen was tested in parallel with the test cell suspension alone. Data analysis was performed with a commercial DNA analysis software program (Cytologics, Coulter Corp.) using an S-fit method for cell-cycle kinetic analysis. A minimum of 5,000 cells (range, 5,000 to 30,000 cells; mean, 20,000) were analyzed for each case. Cytosmear preparations of the FCM cell suspension were examined microscopically and correlated with the hematoxylin-andeosin-stained tissue sections of the corresponding surgical pathology specimen.

\section{Image Analysis}

Air-dried fresh touch imprints of tumor tissue and cytosmear preparations from FCM cell suspension prepared for IA were fixed in $10 \%$ buffered formalin for 30 minutes, rinsed for 5 minutes in deionized water, and allowed to air dry briefly. The slides were then treated for 60 minutes in $5 \mathrm{~N}$ hydrochloric acid to hydrolyze the nuclear DNA. ${ }^{22}$ The slides were stained for 1 hour with Azure A Feulgen (CAS DNA staining kit, Cell Analysis Systems [CAS], Inc., Elmhurst IL), rinsed, dehydrated with three 3-minute changes of absolute ethanol, cleared in xylene, and mounted with coverslips. Analysis was performed using the CAS model 200 image analysis system, implementing the fully integrated system of calibration slides, and quantititative DNA analysis software module. ${ }^{23}$ Only cells identified as tumor cells or epithelial cells were selected for analysis. A minimum of 60 cells were analyzed in each case (range, 60 to 249 cells; mean, 171 cells).

\section{INTERPRETATION OF HISTOGRAMS}

All histograms were interpreted independently and matched with their perspective cases after the data were tabulated. Histograms were interpreted as DNA-diploid or DNA-aneuploid (nondiploid), and DNA ploidy was quantitated using the DNA index (DI). In FCM, the DI 


\section{Original Article}

represents the ratio of the mean channel number of the specimen's G0/G1 peak to the mean channel number of the control G0/G1 peak. Tumors were interpreted as DNA-diploid if there was a single G0/G1 peak containing $90 \%$ or more of the cells and had a DI in the range of 0.95 to 1.05 . Tumors were interpreted as DNA-aneuploid if the DI was outside the diploid range, more than one peak were present, or more than $10 \%$ of the cells were present in the $\mathrm{G} 2 / \mathrm{M}$ phase ${ }^{24}$ without an appreciable Sphase activity. The DNA histogram was considered nondiagnostic when the cytosmear preparation did not contain tumor cells, when large amounts of necrotic debris and/or inflammatory cells were present on the cytosmear preparation, or when the coefficient of variation $(\mathrm{CV})$ of the diploid peak exceeded $7 \%$.

In IA, tumors were interpreted as DNA-diploid if the DI of a single $G 0 / G 1$ peak fell within the diploid range of 0.88 to 1.12 . The measured DI was computed by dividing the modal mass value of the test cells by the known DNA content value of the control cells in picograms ( 7.18 pg). ${ }^{25}$ Tumors were interpreted as aneuploid if the DI fell outside the diploid range, more than $20 \%$ of the cells were present in the $\mathrm{G} 2 / \mathrm{M}$ phase, or more than $25 \%$ of the cells fell beyond the main diploid peak. The $\mathrm{CV}$ of the diploid or main aneuploid peak was measured in each case.

DNA histograms of the discordant cases in IAT/FCM comparison were analyzed further to determine whether discordance was true or false. In "true discordance," the discordance was due to the detection of distinctly different cell populations that showed significant variability in DI and number of cells comprising the G0/G1 peak, by IAT and FCM. In "false discordance," the same cell populations were detected on FCM and IAT histograms but were interpreted differently. Papanicolaou- and WrightGiemsa-stained touch imprints and flow cell suspension smears of the tumor sample were microscopically examined in all discordant cases.

\section{RESULTS}

Eighty-four specimens were analyzed. IAT, IAF, and FCM results were available for most cases. Interpretations from IA histograms of less than 60 cells or FCM of non- diagnostic material were eliminated from the study. Results of DNA analysis of tumors examined are summarized in Table 2.

Comparative DNA analyses using IAT/FCM, IAF/ FCM, and IAT/IAF were performed. Concordance was described as cases in agreement regarding their ploidy status, that is concordant diploid or concordant aneuploid. IAT/FCM comparison showed an $87 \%$ concordance rate. Sixteen cases were concordant diploid and 44 cases were concordant aneuploid (Fig. 1). Correlation between concordance rates of IAT/FCM, IAF/FCM, and IAT/IAF showed no significant difference $(P>0.05$, computed via chi-square test). There were nine discordant cases (13\%), six cases showed DNA-aneuploidy only by IAT, and three cases showed DNA-aneuploidy detected only by FCM. False discordance accounted for $67 \%$ (six cases) of the discordant cases in IAT/FCM, and true discordance was seen in three cases. Table 4 summarizes the results of the comparative DNA analysis performed on all tumors and Table 5 shows in detail the nine discordant cases.

\section{DISCUSSION}

Flow cytometric and image analyses are two different techniques used in quantitative DNA analysis of solid tumors. Flow cytometric analysis measures fluorescence emission of a DNA-bound dye, propidium iodide, excited by a light beam. It is usually performed on a single cell suspension prepared by mechanical or enzymatic disaggregation of a tumor sample, followed by filtration through nylon mesh and centrifugation to remove cell clumps and debris. ${ }^{20}$ Flow cytometric analysis has the advantage of measuring large numbers of cells $(5,000$ to 50,000 cells), and thus the results generally are statistically significant. ${ }^{17.26}$ Image analysis uses a video-based interactive cytometer that measures the sum of the optical density of Feulgen-stained nuclei to calculate the quantity of DNA. ${ }^{23}$ Image analysis can be performed on fresh touch imprints, fine-needle aspiration specimens, paraffin-embedded sections, or cytospin preparations. Image analysis has the advantage of visual inspection of the cells examined, therefore eliminating inflammatory and benign stromal cells from the analysis. ${ }^{17,18,26.27}$ Image analysis histograms,

TABLE 2. Summary of DNA Analysis of Tumors

\begin{tabular}{|c|c|c|c|c|c|c|c|}
\hline & \multirow{2}{*}{$\begin{array}{c}\text { No. of Cases } \\
\text { Examined }\end{array}$} & \multicolumn{2}{|c|}{ Ploidy } & \multicolumn{2}{|c|}{ No. of Cells Analyzed } & \multicolumn{2}{|c|}{$C V(\%)$} \\
\hline & & Diploid & Aneuploid & Mean & Range & Mean & Range \\
\hline IAT & 77 & 22 & 55 & 193 & $77-249$ & 6.98 & $2.9-14$ \\
\hline IAF & 80 & 23 & 57 & 154 & $60-224$ & 9.23 & $4.4-19.1$ \\
\hline FCM & 76 & 25 & 51 & $20 \mathrm{~K}$ & $5-30 \mathrm{~K}$ & 5.02 & $2.4-9.7$ \\
\hline
\end{tabular}

$\mathrm{CV}=$ coefficient of variation, calculated for diploid or main aneuploid peak: $\mathrm{K}=1,000$ (figures given in thousands); IAT = image analysis performed on touch imprints: $\mathrm{IAF}=$ image analysis 
Flow and Image DNA Analysis
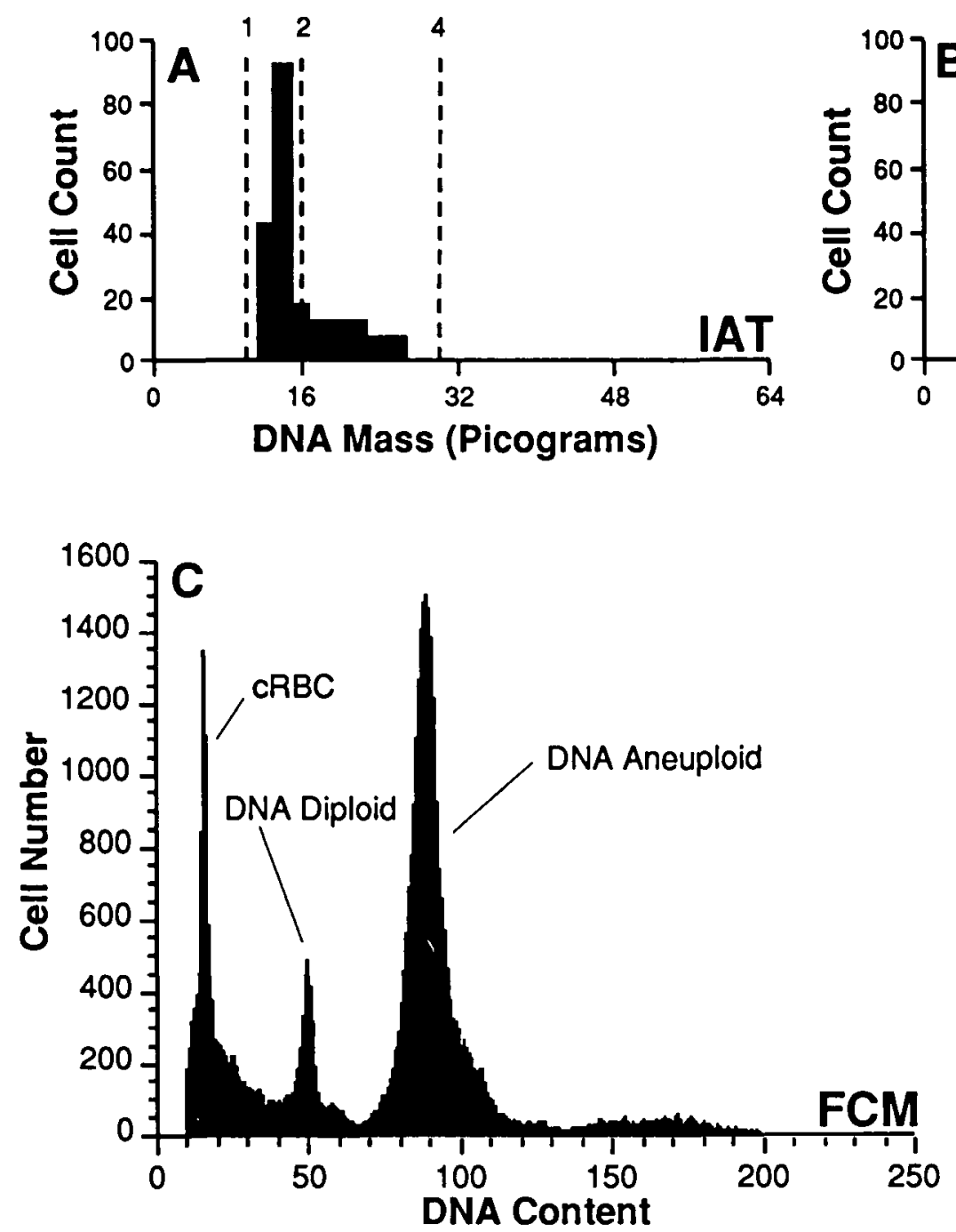

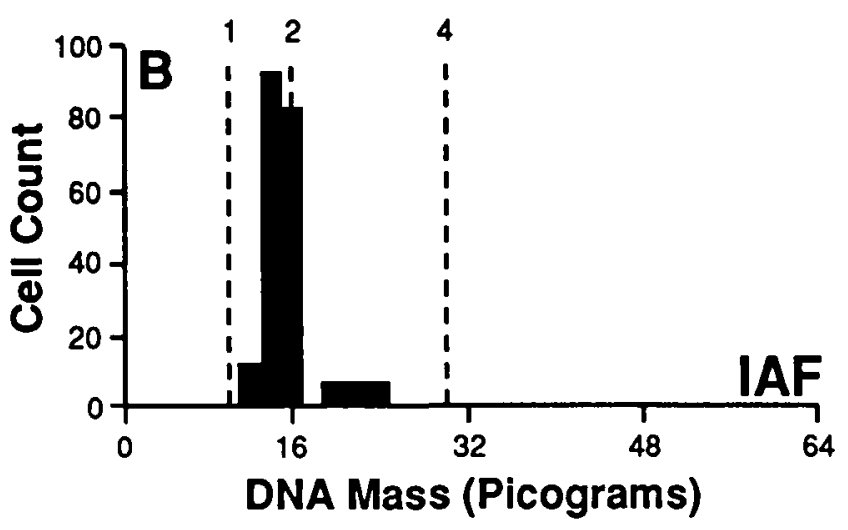

FIGS. 1A-C. An adenocarcinoma of the colon showing concordant aneuploidy in all three comparisons: IAT/ FCM. IAT/IAF, and IAF/FCM. A, B.C. DNA histograms of IAT (image analysis of touch imprints), IAF (image analysis of flow cell suspension cytosmears), and FCM (flow cytometric analysis) showing predominant DNAaneuploid cell populations having DIs of $1.63,1.84,1.72$, respectively. however, have lower resolution and higher $\mathrm{CV}$ compared to FCM, as a result of the smaller number of cells analyzed (50 to 250 cells). ${ }^{9,26.28}$

Comparative quantitative DNA analysis studies using FCM and IA have been performed by other investigators on fresh or paraffin-embedded tissue, ${ }^{8.10-14,16,17.26 .28-34}$ fineneedle aspirations, or body fluids. ${ }^{15.18 .27}$ These studies showed high rates of concordance ranging from $76 \%$ to $91 \%$, thus yielding discordance rates ranging from $24 \%$ to $9 \%$. The discordance in most of the studies was due to aneuploid cell populations detected only by IA and missed by FCM. ${ }^{12,13.15} \mathrm{~A}$ few investigators have reported DNAaneuploidy detected only by FCM. ${ }^{9.29}$ Explanations for missed DNA-aneuploidy by FCM include (1) that aneuploid cells are more fragile and are lost during the filtration and separation steps in preparation of FCM cell suspension ${ }^{8.12 .16}$; (2) that a dilutional effect by inflammatory cells, stromal cells, and diploid epithelial cells makes it difficult to detect small aneuploid populations ${ }^{10.17 .18}$; (3) that the enlarged atypical nuclei of neoplastic cells are well visualized and can be separated and analyzed by $\mathrm{IA}^{16}$; (4) the misinterpretation of FCM histograms due to inability to distinguish DNA-aneuploid cell populations in the tetraploid region from diploid cells present in the G2/M phase. ${ }^{8.12 .16}$ Possible explanations for missed DNA-aneuploid cell populations by IA, yet detected by FCM are (1) sampling error due to the smaller sampling area of touch imprints ${ }^{12}$ or (2) lower resolution and higher CV of IA histograms makes it difficult to distinguish near-diploid DNA-aneuploid cell populations from those that are diploid. 8.19

The aim of our study was to determine objectively which factors are independently responsible for the discordance between FCM and IA. We performed a threeway comparison between FCM, IA performed on tumor touch imprints (IAT), and IA performed on cytosmear 
preparations of the same cell suspension used for FCM (IAF). We then assessed the effects of the various factors on concordance rates. In the first comparison, where we compared FCM to IAT (IAT/FCM), the apparatus and methodology used were different (flow cytometer versus image analyzer) and the cell population examined was different (flow cell suspension versus touch imprints) (Table 3). The differences in cell population is due to sampling area differences and possible loss of aneuploid cells during FCM cell suspension preparation (Table 3). When comparing IAT with IAF (IAT/IAF), the apparatus and methodology were constant (image analyzer used in both instances), but the cell population was different (flow cell suspension versus touch imprints). Therefore, if there is discordance between IAT and IAF, it is probably not due to a difference in apparatus and methodology, but rather is more likely due to differences in cell population. In comparisons of IAF and FCM (IAF/FCM), the same cell populations were examined because we analyzed the same cell suspensions. Therefore, if there is any disagreement between IAF and FCM, it is most probably due to the difference in apparatus and methodology (flow cytometer versus image analyzer). If differences in cell populations and apparatus and methodology were truly significant contributing factors to discordance, then IAT/IAF and IAF/FCM comparisons should have shown higher concordance rates (where we controlled for one variable and examined the other) than IAT/FCM comparison (where both variables were contributing to discordance). Our results showed that IAT/FCM comparison had an $87 \%$ concordance rate (60 of 69 tumors), which is similar to previously reported series (Fig. 1). IAF/FCM and IAT/ IAF comparisons showed concordance rates of $88 \%$ and $90 \%$, which are not significantly different from that of IAT/FCM (Table 4). This suggests that differences in apparatus and methodology and differences in sampling area

TABLE 3. COMPARISONS AND VARIABLES (FACTORS) AFFECTING CONCORDANCE

\begin{tabular}{llc}
\hline Comparisons & $\begin{array}{c}\text { Apparatus and } \\
\text { Methodology }\end{array}$ & Cell Population \\
\hline$\frac{\text { IAT }}{\text { FCM }}$ & $\frac{\text { Image analyzer }}{\text { Flow cytometer }}$ & $\frac{\text { Touch imprints }}{\text { Flow cell suspension }}$ \\
$\frac{\text { IAT }}{\text { IAF }}$ & $\frac{\text { Image analyzer }}{\text { Image analyzer }}$ & $\frac{\text { Touch imprints }}{\text { Flow cell suspension }}$ \\
$\frac{\text { IAF }}{\text { FCM }}$ & $\frac{\text { Image analyzer }}{\text { Flow cytometer }}$ & $\frac{\text { Flow cell suspension }}{\text { Flow cell suspension }}$ \\
\hline
\end{tabular}

In IAT/FCM comparison there are differences in apparatus and methodology as well as in cell population: therefore. both variables are contributing to discordance. In the other comparisons. we controlled for one variable (apparatus and methodology in IAT/IAF and cell population in (AF/FCM) and assessed the other.

See Table 2 for definitions of acronyms.
TABLE 4. SUMMARY OF COMPARATIVE DNA ANALYSES OF TUMORS

\begin{tabular}{lccccc}
\hline & $\begin{array}{c}\text { Total No. } \\
\text { of Cases } \\
\text { Analyzed }\end{array}$ & $\begin{array}{c}\text { Concordance } \\
\text { Total No. } \\
(\%)\end{array}$ & $\begin{array}{c}\text { Discordance } \\
\text { Total No. }\end{array}$ & False & True \\
\hline & & & & & \\
IAT/FCM & 69 & $60(87 \%)$ & 9 & 6 & 3 \\
IAT/IAF & 73 & $66(90 \%)$ & 7 & & \\
IAF/FCM & 72 & $63(88 \%)$ & 9 & & \\
\hline
\end{tabular}

IAF/FCM. IAT/IAF, and IAF/FCM: Comparisons of IAT vs. FCM. IAT vs. IAF, and IAF vs. FCM show no significant difference in concordance rates. False discordance accounted for most of the discordant cases.

See Table 2 for definitions of acronyms.

or FCM cell processing are not significant contributing factors to discordance between IA and FCM.

DNA histograms of the discordant cases in the IAT/ FCM comparison were analyzed further to determine whether discordance was true or false. By our definition, in true discordance, distinctly different cell populations showing significant variation in DI, number of cells in G0/G1 peak, and number of peaks were detected by IA and FCM. In false discordance, however, the same cell populations were detected on FCM and IA histograms but were interpreted differently. An example of false discordance between IAT and FCM is illustrated in Figure 2 (discordant case 3, Table 5), for which both histograms showed similar G0/G1 peaks located in the peridiploid region, but were interpreted differently as DNA-aneuploid in IAT (DI = 1.16) and DNA-diploid in FCM (DI = 0.97). The IAF histogram in this case showed a cell population with features similar to those seen on IAT and FCM (single G0/G1 peak containing more than $90 \%$ of cells in peridiploid region, $\mathrm{DI}=1.11$ ), confirming that these are the same cell populations detected.

In this study, tumors were interpreted as DNA-diploid if they showed a single G0/G1 peak located in the diploid range (DI of 0.95 to 1.05 in FCM and DI of 0.88 to 1.12 in IA). Tumors showing one or more peaks outside the diploid range were interpreted as DNA-aneuploid. There is wide variability in the literature regarding the criteria used for interpretation of FCM and IA histograms. ${ }^{25,35.36}$ In FCM, many authors define DNA-diploidy as a single G0/G1 peak, regardless of DI. ${ }^{35,37}$ This is used especially in the examination of formalin-fixed, paraffin-embedded samples in which there is a lack of a suitable standard to be added to the tumor sample, and poor quality histograms occur due to excessive nuclear fragments and wide CVs. ${ }^{36.38}$ In fresh specimens, however, normal human peripheral blood lymphocytes serving as an internal standard are added to the tumor sample before staining with the fluorochrome, and high-resolution DNA histograms are usually obtained. ${ }^{36.38}$ There still remains some compli- 
Flow and Image DNA Analysis
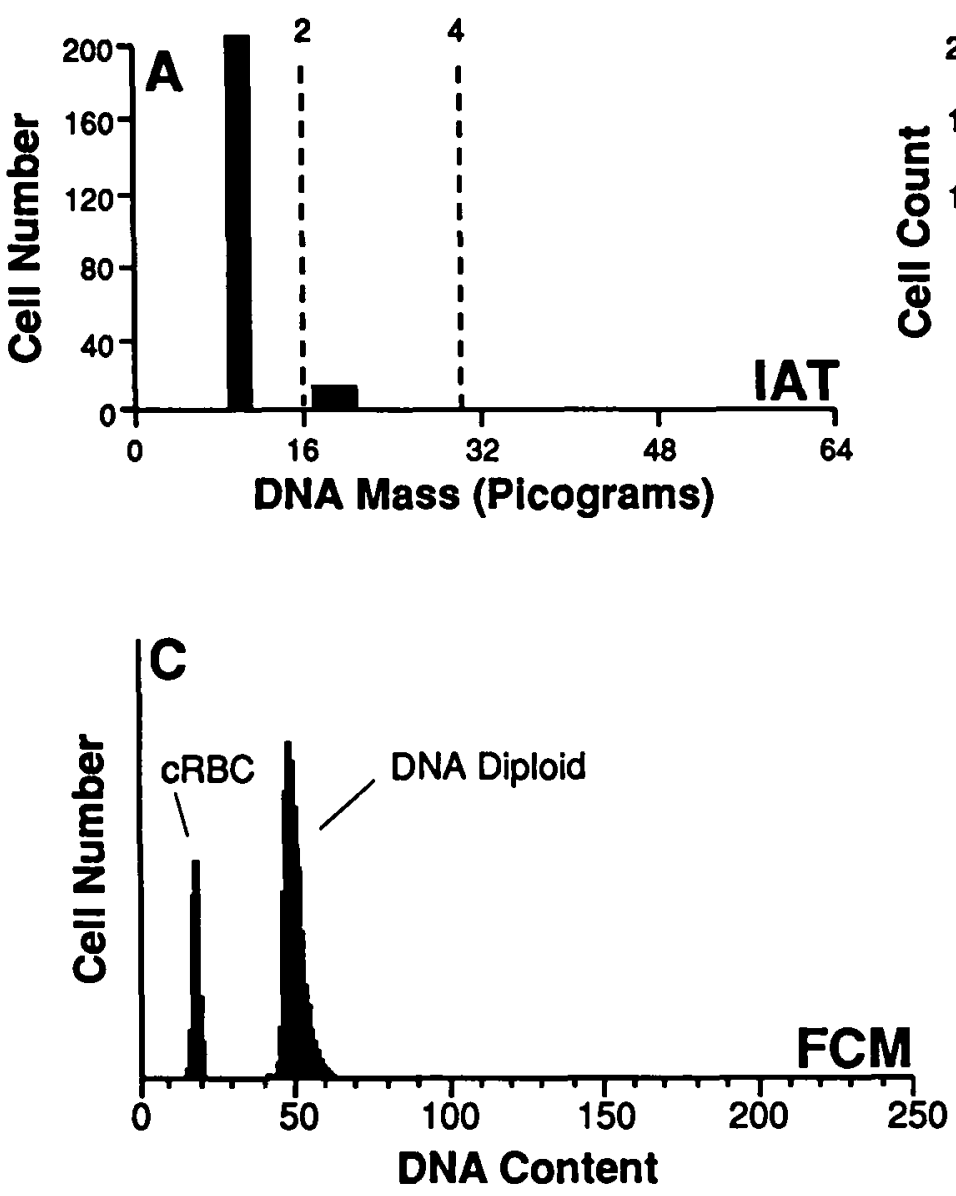

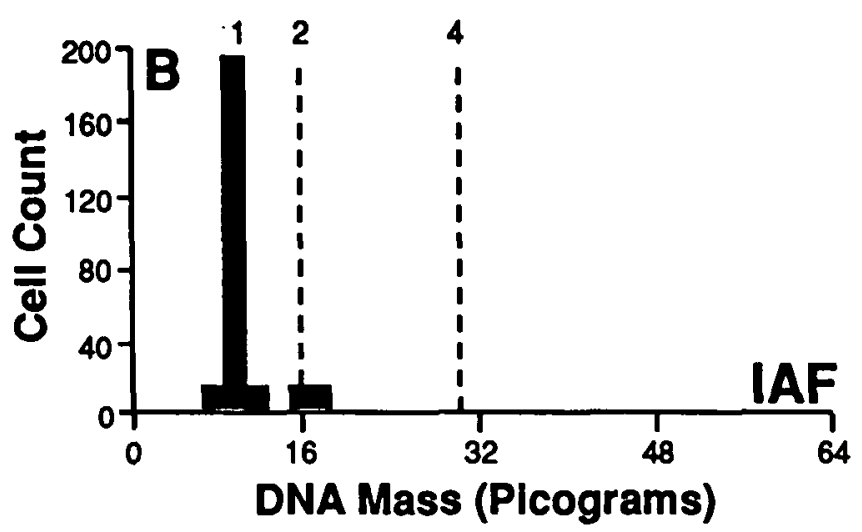

FIGS. 2A-C. An example of false discordance between IAT and FCM in an invasive papillary carcinoma of the breast. $A, B, C$. IAT, IAF, and FCM DNA histograms showing similar predominant cell populations with single $\mathrm{GO} / \mathrm{G}_{1}$ peaks in the peridiploid region, containing more than $90 \%$ of the cells and having Dls of $1.16,1.11$, and 0.97 , respectively. These histograms, however. were interpreted differently as aneuploid, diploid, and diploid. cated histograms that are difficult to interpret ${ }^{39}$; therefore, assessment relies heavily on the subjective judgment of individual investigators. ${ }^{40}$

False discordance in our study was seen in six cases (Table 4). Three cases showed DNA-aneuploidy only by IA, whereas the other three cases showed DNA-aneuploidy detected only by FCM (Table 5). All DNA-aneuploid cell populations detected by IAT in this group consisted of single G0/G1 peaks located in the peridiploid region (Fig. 2). The aneuploid cell populations detected only by FCM demonstrated a single peak having a DI of 1.17 in one case, and showed distinctly separate DNA-aneuploid (hypodiploid) peaks in two other cases (Table 5). Another example of false discordance between IAT and FCM is

TABLE 5. DETAILS OF DISCORDANT CASES BETWEEN FCM AND IAT

\begin{tabular}{|c|c|c|c|c|c|c|}
\hline \multirow[b]{2}{*}{ Discordant Cases } & \multicolumn{3}{|c|}{$F C M$} & \multicolumn{3}{|c|}{$I A T$} \\
\hline & $D I$ & $C V(\%)$ & Ploidy & $D I$ & $C V(\%)$ & Ploidy \\
\hline \multicolumn{7}{|l|}{ False Discordance } \\
\hline Case 1 & 1.01 & 4.7 & Diploid & 1.2 & 8.3 & Aneuploid \\
\hline Case 2 & 0.98 & 2.5 & Diploid & 1.16 & 10.6 & Aneuploid \\
\hline Case 3 & 0.97 & 4.1 & Diploid & 1.16 & 2.9 & Aneuploid \\
\hline Case 4 & 1.17 & 4.8 & Aneuploid & 1.11 & 5.6 & Diploid \\
\hline Case 5 & 0.87 & 5.8 & Aneuploid & 0.92 & 12 & Diploid \\
\hline Case 6 & 0.8 & 3.5 & Aneuploid & 0.91 & 4.8 & Diploid \\
\hline \multicolumn{7}{|l|}{ True Discordance } \\
\hline Case 7 & 0.96 & 6.6 & Diploid & 2.74 & 9.1 & Aneuploid \\
\hline Case 8 & 0.93 & 5.8 & Diploid & 2.13 & 6.1 & Aneuploid \\
\hline Case 9 & 0.92 & 5.2 & Diploid & 2.16 & 5.7 & Aneuploid \\
\hline
\end{tabular}

$\mathrm{DI}=\mathrm{DNA}$ index of diploid or main aneuploid peak: $\mathrm{CV}=$ coefficient of variation, calculated See Table 2 for definitions of acronyms. for diploid or main aneuploid peak. 
Original Article
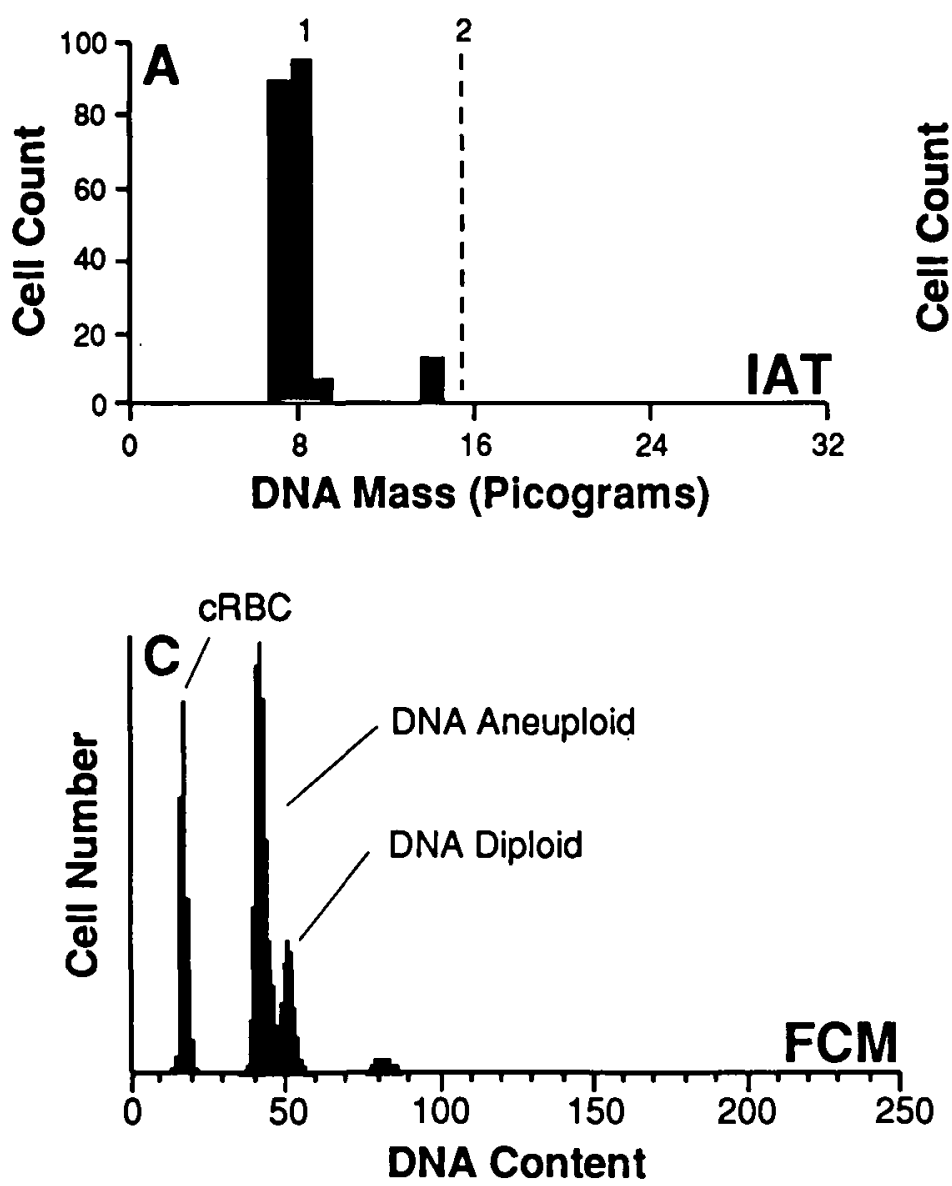

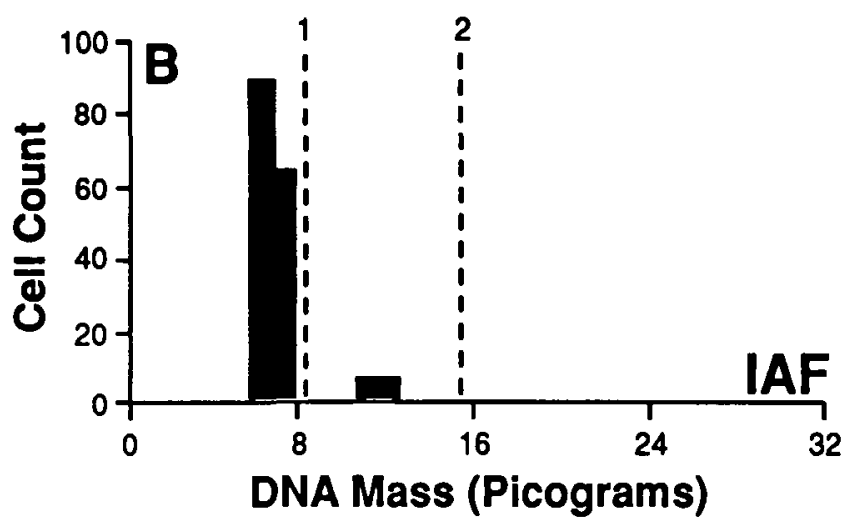

FIGs. 3A-C. A moderately poorly differentiated adenocarcinoma of the ovary showing false discordance between IAT and FCM. $A$. IAT showing a predominant cell population $(85 \%$ of the total number of cells) with a DI of 0.91 . This histogram was interpreted as DNA diploid. $B$. IAF showing a similar DNA histogram to IAT except the DI was 0.77 . C. FCM DNA histogram showing a predominant DNA aneuploid (hypodiploid) cell population with a DI of 0.8 . illustrated in Figure 3 (discordant case 6), in which a definite hypodiploid DNA-aneuploid peak (DI $=0.8$ ) comprising $81 \%$ of the cell population was detected by FCM. IAT showed a similar single G0/G1 peak comprising $85 \%$ of the cell population but was interpreted as DNA-diploid because the DI was 0.91. The peaks seen in FCM and IAT histograms in this case represented the same cell populations, and this was confirmed by the presence of an identical G0/G1 peak detected by IAF in addition to the presence of similar tumor cells on touch imprints and smears of flow cell suspensions prepared from tumor samples. The presence of false discordance in most of the discordant cases $(67 \%)$ suggested that differences as well as difficulties in the interpretation of IA and FCM histograms may contribute significantly to discordance. These differences in interpretation are probably a result of the low resolution and high CV of IA histograms, which makes it difficult to interpret cell populations residing in the peridiploid range.

Three cases showed true discordance between IAT and FCM (Table 4). In all three cases predominant DNAaneuploid cell populations (hypertetraploid) were detected only by IAT, whereas FCM showed pure DNA-diploid populations without increased $\mathrm{CV}$ or $\mathrm{G} 2 / \mathrm{M}$ phase activity
(Table 5). Similar observations have been reported previously. ${ }^{8.12 .16 .41}$ An explanation for the failure of FCM to detect the DNA hypertetraploid cell populations is that hypertetraploid cells are more fragile and therefore more readily lost during the preparation of the flow cell suspension. In our study, IA performed on flow cell suspensions (IAF) in all three true discordant cases showed the same DNA-aneuploid (hypertetraploid) cell populations detected by IAT (Fig. 4). This further supports that loss of aneuploid cells during preparation of FCM cell suspension does not contribute significantly to discordance between IA and FCM. The missed DNA-aneuploidy by FCM in these cases may be a result of dilutional effect by inflammatory cells, stromal cells, and diploid epithelial cells present in the FCM cell suspension. Microscopic examination of smears prepared from flow cell suspension in one case (discordant case 9, Table 5) showed tumor cells with many inflammatory cells in the background, but inflammatory cells were not present in the other two cases.

This study indicates that aneuploid cell loss during FCM cell processing and differences in sampling area do not play a major role in causing discordance between IA and FCM. Instead, the discordance is probably due to 
Flow and Image DNA Analysis
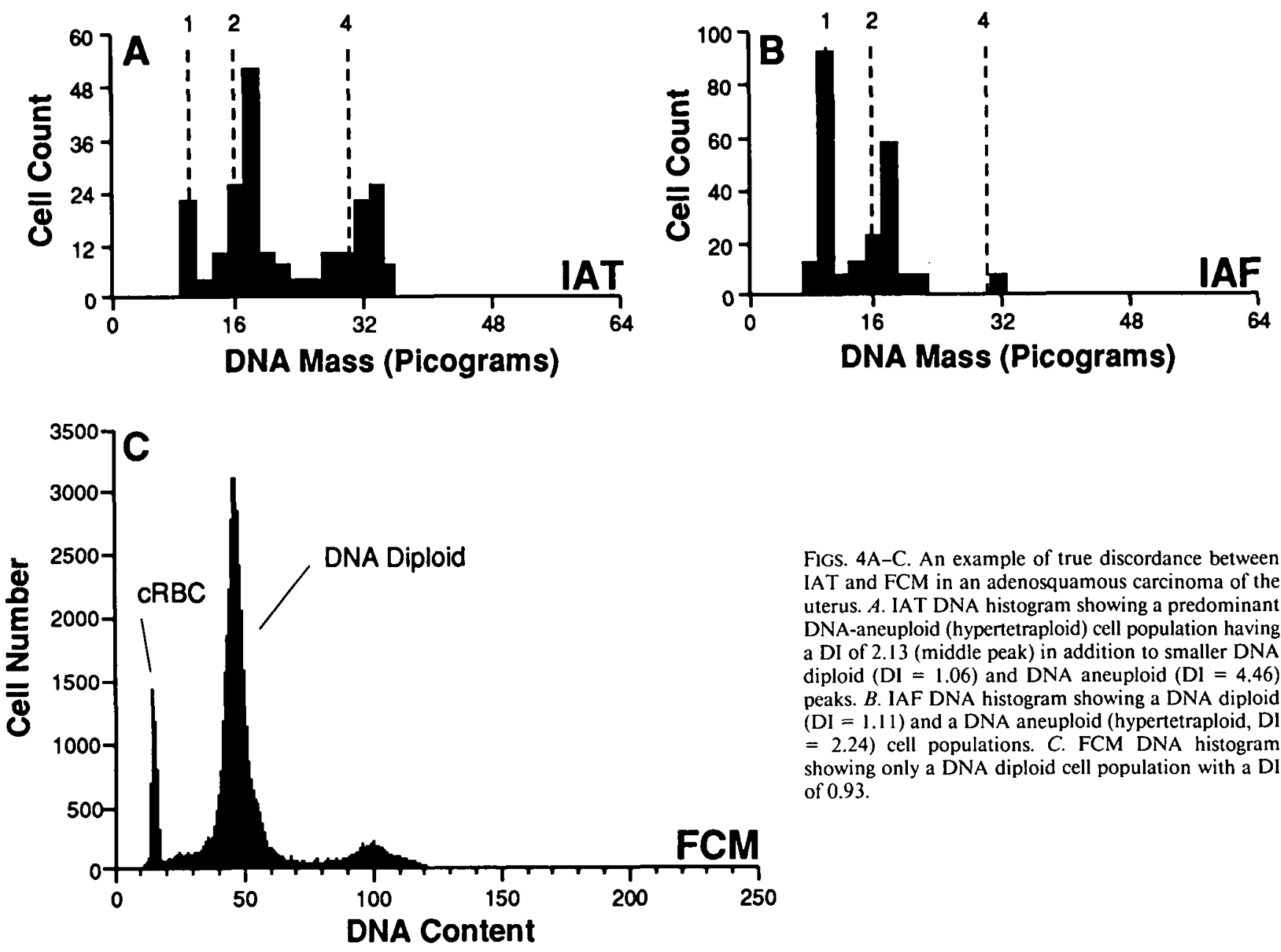

FIGS. 4A-C. An example of true discordance between IAT and FCM in an adenosquamous carcinoma of the uterus. $A$. IAT DNA histogram showing a predominant DNA-aneuploid (hypertetraploid) cell population having a DI of 2.13 (middle peak) in addition to smaller DNA diploid $(\mathrm{DI}=1.06)$ and DNA aneuploid $(\mathrm{DI}=4.46)$ peaks. $B$. IAF DNA histogram showing a DNA diploid $(\mathrm{DI}=1.11)$ and a DNA aneuploid (hypertetraploid, DI $=2.24$ ) cell populations. $C$. FCM DNA histogram showing only a DNA diploid cell population with a DI of 0.93 .

differences in assessing ploidy in the interpretation of histograms and/or dilution of aneuploid cell populations by diploid cells present in the FCM cell suspension. Ideally, IA and FCM should be used on all specimens to combine the higher resolution on the $Y$ axis of DNA histograms obtained by IA (higher sensitivity for detection of minor DNA-aneuploid cell populations), with FCM's higher resolution on the $\mathrm{X}$ axis (lower $\mathrm{CV}$ and increased number of cells analyzed). " However, this may not be practically possible in all cases as a result of cost restraints and lack of adequate material for both studies.

Acknowledgments. The authors thank Trish Robbins for secretarial assistance and Karla Posekany for technical assistance.

\section{REFERENCES}

1. Bocking A, Chatelain R, Biesterfeld S, et al. DNA grading of malignancy in breast cancer. Prognostic validity, reproducibility, and comparison with other classifications. Anal Quant Cytol Histol 1989;11:73-80.

2. Clark GM, Dressler LG, Owens MA, et al. Prediction of relapse or survival in patients with node-negative breast cancer by DNA flow cytometry. N Engl J Med 1989:320:627-633.
3. Coulson PB, Thornthwaite JT, Woolley TW, Sugarbaker EV, Seckinger D. Prognostic indicators including DNA histogram type, receptor content, and staging related to human breast cancer patient survival. Cancer Res 1984;44:4187-4196.

4. Dressler LG, Seamer LC, Owens MA, Clark GM, McGuire WL. DNA flow cytometry and prognostic factors in 1331 frozen breast cancer specimens. Cancer 1988;61:420-427.

5. Barlogie B, Johnston DA, Smallwood L, et al. Prognostic implications of ploidy and proliferative activity in human solid tumors. Cancer Genet Cytogenet 1982;6:17-28.

6. Friedlander ML, Hedley DW, Taylor IW. Clinical and biological significance of aneuploidy in human tumors. J Clin Pathol 1984;37:961-974.

7. Merkel DE, Dressler LG, McGuire WL. Flow cytometry, cellular DNA content, and prognosis in human malignancy. J Clin Oncol 1987;5:1690-1703.

8. Dawson AE, Norton JA, Weinberg DS. Comparative assessment of proliferation and DNA content in breast carcinoma by image analysis and flow cytometry. Am J Pathol 1990; 136:1115-1124.

9. Claud RD III, Weinstein RS, Howeedy A, Straus AK, Coon JS. Comparison of image analysis of imprints with flow cytometry for DNA analysis of solid tumors. Mod Pathol 1989;2:463-467.

10. Valdes Martin del Campo M, Strang P, Stendahl U, Stenkvist B. DNA determination in endometrial carcinoma by flow and image cytometry. Acta Oncol 1989;28:607-609.

11. Falkmer UG, Hagmar T, Auer G. Efficacy of combined image and flow cytometric DNA assessments in human breast cancer: A methodological study based on a routine histopathological ma- 


\section{Original Article}

terial of 2024 excised tumour specimens. Analyt Cell Pathol 1990;2:297-312.

12. Bauer TW, Tubbs RR, Edinger MG, et al. A prospective comparison of DNA quantitation by image and flow cytometry. Am J Clin Pathol 1990;93:322-326.

13. Fausel RE, Burleigh W, Kaminsky DB. DNA quantification in colorectal carcinoma using flow and image analysis cytometry. Analyt Quant Cytol Histol 1990;12:21-27.

14. Fallenius AG, Askensten UG, Skoog LK, Auer GU. The reliability of microspectrophotometric and flow cytometric nuclear DNA measurements in adenocarcinomas of the breast. Cytometry 1987;8:260-266.

15. Koss LG, Wersto RP, Simmons DA, et al. Predictive value of DNA measurements in bladder washings. Comparison of flow cytometry, image cytophotometry, and cytology in patients with a past history of urothelial tumors. Cancer 1989;64:916-924.

16. Cornelisse CJ, Van Driel-Kulker AM. DNA image cytometry on machine-selected breast cancer cells and a comparison between flow cytometry and scanning cytophotometry. Cytometry 1985;6: 471-477.

17. Wilbur DC, Zakowski MF, Kosciol CM, Sojda DF, Pastuszak WT DNA ploidy in breast lesions. A comparative study using two commercial image analysis systems and flow cytometry. Analyt Quant Cytol Histol 1990; 12:28-34.

18. Schneller J, Eppich E, Greenebaum E, et al. Flow cytometry and feulgen cytophotometry in evaluation of effusions. Cancer 1987;59:1307-1313.

19. Wallin G, Askensten U, Backdahl M, et al. Cytochemical assessments of the nuclear DNA distribution pattern by means of image and flow cytometry in thyroid neoplasms and in non-neoplastic thyroid lesions. Acta Chir Scand 1989;155:251-258.

20. Riley RS, Mahin EJ. Clinical applications of flow cytometry. ASCP Workshop 9072, San Francisco, CA, 1990.

21. Krishan A. Rapid flow cytofluorometric analysis of mammalian cell cycle by propidium iodide staining. J Cell Biol 1975;66:188-193.

22. De Cresce R. The CAS 100: A computerized microscope image analysis system. Lab Med 1986; 17:163-165.

23. Bacus JW, Grace LJ. Microscope system for standardized cell measurements and analyses. Appl Optics 1987;26:3280-3293.

24. Baildam AD, Zaloudik J, Howell A, et al. DNA analysis by flow cytometry, response to endocrine treatment and prognosis in advanced carcinoma of the breast. Br J Cancer 1987; 55:553-559.

25. Taylor SR, Titus-Ernstoff L, Stitely $S$. Central values and variation of measured nuclear DNA content in imprints of normal tissues, determined by image analysis. Cytometry 1989;10:382-387.

26. Oud PS, Hanselaar AGJM, Pahlplatz MMM, Meijer JWR, Vooijs GP. Image DNA-index (ploidy) analysis in cancer diagnosis. Appl Optics 1987;26:3349-3355.

27. Rijken A, Dekker A, Taylor S, et al. Diagnostic value of DNA analysis in effusions by flow cytometry and image analysis. A prospective study on 102 patients as compared with cytologic examination. Am J Clin Pathol 1991;95:6-12.

28. Rodenburg CJ, Ploem-Zaaijer JJ, Cornelisse CJ, et al. Use of DNA image cytometry in addition to flow cytometry for the study of patients with advanced ovarian cancer. Cancer Res 1987;47:39383941.

29. Contis L, Brown A, Coates C, Blank M, Krause JR. A prospective study of DNA ploidy in tumors quantitated by image versus flow cytometry. Am J Clin Pathol 1991;95:274.

30. Askensten UG, von Rosen AK, Nilsson RS, Auer GU. Intratumoral variations in DNA distribution patterns in mammary adenocarcinomas. Cytometry 1989; 10:326-333.

31. McFadden PW, Clowry LJ, Daehnert K, Hause LL, Koethe SM. Image analysis confirmation of DNA aneuploidy in flow cytometric DNA distributions having a wide coefficient of variation of the G0/G1 peak. Am J Clin Pathol 1990;93:637-642.

32. Weger A-R, Falkmer UG, Schwab G, et al. Nuclear DNA distribution pattern of the parenchymal cells in adenocarcinomas of the pancreas and in chronic pancreatitis. A study of archival specimens using both image and flow cytometry. Gastroenterology 1990;99: 237-242.

33. Oud PS, Pahlplatz MMM, Beck JLM, et al. Image and flow DNA cytometry of small cell carcinoma of the lung. Cancer 1989;64: 1304-1309.

34. Strang $P$, Lindgren A, Stendahl U. Comparison between flow cytometry and single cell cytophotometry for DNA content analysis of the uterine cervix. Acta Radiol [Oncol] 1985;24:337-341.

35. Wersto RP, Liblit RL, Koss LG. Flow cytometric DNA analysis of human solid tumors: A review of the interpretation of DNA histograms. Hum Pathol 1991;22:1085-1098.

36. Frierson HF Jr. The need for improvement in flow cytometric analysis of ploidy and S-phase fraction (editorial). Am J Clin Pathol 1991;95:439-441.

37. Hiddemann W, Schumann J, Andreeff M, et al. Convention of nomenclature for DNA cytometry. Cytometry 1984;5:445-446.

38. Dressler LG, Bartow SA. DNA flow cytometry in solid tumors: Practical aspects and clinical applications. Semin Diagn Pathol 1989;6:55-82.

39. Joensuu H, Kallioniemi OP. Different opinions on classification of DNA histograms produced from paraffin-embedded tissue. Cytometry 1989;10:711-717.

40. Vindelov LL, Christensen IJ. A review of techniques and results obtained in one laboratory by an integrated system of methods designed for routine clinical flow cytometric DNA analysis. Cytometry 1990; 11:753-770.

41. Lee AKC, Dugan J, Hamilton WM, et al. Quantitative DNA analysis in breast carcinomas: A comparison between image analysis and flow cytometry. Mod Pathol 1991;4:178-182. 